\title{
Histo pathological analysis of hysterectomy specimens in tertiary care center: two year study
}

\author{
Patel A.S. ${ }^{1}$, Shah K.J. ${ }^{2}$ \\ ${ }^{1}$ Dr. Amita S. Patel, Assistant Professor, ${ }^{2}$ Dr. Kamlesh J Shah, Professor \& Head, both authors are affiliated with \\ Department of Pathology, GMERS Medical College, Halar Road, Valsad, Gujrat, India.
}

Corresponding Author: Dr. Kamlesh J Shah, Professor \& Head, Pathology Department, GMERS Medical College, Halar Road, Valsad. Email id: drkjs1964@gmail.com

\begin{abstract}
Background: The uterus is a major female hormone-responsive reproductive pear-shaped organ located within the pelvic region. The gross morphology of uterus quite dramatically changed throughout life by changing levels of ovarian hormones. A hysterectomy is done for many reasons including the ridding of tumours both benign and malignant. It is the most commonly performed gynecological surgical procedure throughout the world. Materials and Methods: This study was undertaken to identify the different types of pathologies in hysterectomy specimens and to correlate the findings with the different age group and clinical indications. In the present study, 303 cases were studied over a period of two years from January 2016 to December 2017. Surgical specimens were formalin fixed and the tissue was adequately processed for histopathological examination. The sections were stained routinely with hematoxylin and eosin stain. Results: Of the 303 cases, half of the cases $(50.8 \%)$ were encountered in the age group of 40 - 49 years which was the most common age group. Fibroid uterus (38.6\%) and uterine prolapse (32.6\%) were the most common clinical indications for hysterectomy. The most common pathology identified was leiomyoma $(42.2 \%)$ in myometrium. In cervix most common finding was chronic cervicitis $(28.1 \%)$. Histopathological examination confirmed the clinical and gross diagnosis in majority of the cases. Conclusions: The present study provides a fair insight into the histological patterns of lesions in hysterectomy specimens in our institution. A wide range of lesions are encountered when hysterectomy specimens are subjected to histopathological examination. Few lesions were encountered as incidental findings. Hence, it is important that every hysterectomy specimen should be subjected to detailed gross and histopathological examination for better postoperative management.
\end{abstract}

Keywords: Hysterectomy, Histopathology, Leiomyoma, Uterine prolapse, Menorrhagia.

\section{Introduction}

The uterus is a vital reproductive and hormone responsive organ is subjected to many non-neoplastic and neoplastic conditions. Many treatment options are available including medical and conservative surgical but hysterectomy still the second most frequently performed major surgical procedure in females worldwide next to cesarean section [1]. It is the treatment of choice for many indications which include dysfunctional uterine bleeding, fibroids, gynecological cancers and obstetric disorders [2]. Hysterectomy is done by the vaginal or abdominal route, or with the help of laparoscope. Histopathological examinations of hysterectomy specimens have both diagnostic and therapeutic significance [3]. Hence, this study was

Manuscript received: $20^{\text {th }}$ January 2018

Reviewed: $30^{\text {th }}$ January 2018

Author Corrected: $6^{\text {th }}$ February 2018

Accepted for Publication: $11^{\text {th }}$ February 2018 conducted to study various gross and histopathological patterns of lesions in uterus and cervix of the hysterectomy specimens received and their clinicopathological correlation in our institute. The aim of the study was to evaluate the histopathological features of varied lesions of uterus and cervix, their distribution in relation to age, different mode of clinical presentation and clinical indications for hysterectomy at tertiary care hospital.

\section{Methods}

This is the retrospective study done in the department of pathology, GMERS medical college, Valsad over a period of 2 years from January 2016 to December 2017. The female patients with age more than 20 years with uterine and cervical indications for hysterectomy 
Original Research Article

irrespective of type of surgery were included in the study. Hysterectomy performed for obstetrical causes were also included in study. Hysterectomies done by abdominal or vaginal route were included in present study. Hysterectomy specimens with indications of tubal or ovarian pathology were excluded from the study. Total 303 hysterectomy specimens were included and evaluated for this study.

Clinical details and relevant history of the patients were obtained from the requisition forms received along with specimens and from clinical case sheets were entered in the proforma for the study and analyzed.

The Hysterectomy specimens received were immediately transferred into $10 \%$ formalin saline in the ratio of 1:10. After 24 hours fixation, the specimen was examined grossly for size, wall thickness and any mass present and necessary sections were taken from uterus that includes endometrium, myometrium and serosa from fundus, body and lower -uterine segment. Additional minimum of 3 sections from the lesion were taken if required, depending on the pathology present. Similarly, minimum 2 sections were obtained from cervix that includes endocervix and ectocervix from both lips of cervix.

Minimum 3 sections from the lesion, if any were also obtained. The tissue pieces were then processed in automated tissue processor and then paraffin blocks were made and care was taken for preparation of paraffin blocks and proper labeling on blocks and slides. Then the sections were examined by light microscope and results are obtained.

\section{Result}

A total of 303 cases were studied over a period of two years. The hysterectomies were distributed over a wide age range of 20 years to 70 years. The most common age group undergoing hysterectomy appeared to be $40-49$ years with 154 $(50.8 \%)$ cases followed by $69(22.8 \%)$ cases in 30-39 years age group (Table-1).

The commonest complaint was menorrhagia in $126(41.6 \%)$ cases followed by something coming out of vagina in 94 $(31 \%)$ cases, abdominal pain in $50(16.5 \%)$ cases, abdominal mass in $31(10.3 \%)$ cases, post-menopausal bleeding in $1(0.3 \%)$ case and per vaginal discharge in $1(0.3 \%)$ case. Most common mode of hysterectomy was through abdominal route.

The most common histopathological finding in the uterine endometrium was atrophic endometrium (cystic or pressure atrophy) seen in $88(29 \%$ ) cases followed by endometrial hyperplasia $16(5.3 \%)$ cases and endometrial polyp in $8(2.7 \%)$ cases. Endometrial carcinoma comprised of only 3(1\%) cases (Figure-1) Low grade endometrial stromal sarcoma $1(0.3 \%)$ case and placenta accrete $1(0.3 \%)$ case also diagnosed. Myometrium was unremarkable in $136(42.9 \%)$ cases. The most common myometrial pathology reported was leiomyoma $128(42.2 \%)$ followed by adenomyosis $25(8.3 \%)$. About 9(3\%) patients had both leiomyoma and adenomyosis. 4(1.3\%) cases of adenomyoma were also diagnosed (Table2) (Figure-2\&3)

Majority number of cases showed chronic cervicitisas the main cervical pathology in $85(28.1 \%)$ cases followed by chronic papillary cervicitis in 52(17.2\%) cases. Both chronic cervicitis and squamous metaplasia is seen in about $43(14.2 \%)$ cases. Cervical malignancy encountered in 8 cases, out of which 7(2.3\%) cases of Squamous cell carcinoma and $1(0.3 \%)$ case of mucinous endocervical adenocarcinoma. (Figure-4)Other less frequent cervical pathologies encountered were endocervical polyps, cervical intraepithelial neoplasia and malignant tumors. No remarkable pathology was found in $73(24.1 \%)$ cases (Table -3$)$

Table-1: Age distribution of hysterectomy specimens

\begin{tabular}{|c|c|c|c|}
\hline Sr. No. & Age group (in years) & Total No. of cases & Percentage \\
\hline 1 & $20-29$ & 4 & $1.3 \%$ \\
\hline 2 & $30-39$ & 69 & $22.8 \%$ \\
\hline 3 & $40-49$ & 154 & $50.8 \%$ \\
\hline 4 & $50-59$ & 50 & $16.5 \%$ \\
\hline 5 & $60-69$ & 25 & $8.3 \%$ \\
\hline 6 & $\geq 70$ & 1 & $0.3 \%$ \\
\hline 7 & & 303 & $100 \%$ \\
\hline
\end{tabular}




\section{Original Research Article}

Table-2: Distribution of various types of uterine lesions.

\begin{tabular}{|c|c|c|c|}
\hline Sr. No. & Uterine lesions & Total No. of cases & Percentage \\
\hline 1 & leiomyoma & 128 & $42.2 \%$ \\
\hline 2 & Adenomyosis & 25 & $8.3 \%$ \\
\hline 3 & Leiomyoma + Adenomyosis & 9 & $3 \%$ \\
\hline 4 & Adenomyoma & 4 & $1.3 \%$ \\
\hline 5 & Atrophy/cystic atrophy/ pressure atrophy & 88 & $29 \%$ \\
\hline 6 & Endometrial hyperplasia & 16 & $5.3 \%$ \\
\hline 7 & Endometrial polyp & 8 & $2.7 \%$ \\
\hline 8 & Endometrial carcinoma & 3 & 1 \\
\hline 9 & Low grade endometrial stromal sarcoma & 1 & $0.3 \%$ \\
\hline 10 & Placenta accrete (Chorionic villi) & 1 & $0.3 \%$ \\
\hline 11 & unremarkable & 20 & $6.6 \%$ \\
\hline $\mathbf{1 2}$ & \multicolumn{2}{|c|}{ Total } & $\mathbf{3 0 3}$ \\
\hline
\end{tabular}

The most common myometrial pathology reported was leiomyoma 128 (42.2\%) followed by adenomyosis 25 (8.3\%). About $9(3 \%)$ patients had both leiomyoma and adenomyosis. 4 (1.3\%) cases of adenomyoma were also diagnosed

Table-3: Distribution of cervical lesions.

\begin{tabular}{|c|c|c|c|}
\hline Sr. No. & Cervical lesions & Total No. of cases & Percentage \\
\hline 1 & Chronic cervicitis & 85 & $28.1 \%$ \\
\hline 2 & Chronic papillary endocervicitis & 52 & $17.2 \%$ \\
\hline 3 & Squamous metaplasia & 30 & $9.9 \%$ \\
\hline 4 & Chronic cervicitis + Squamous metaplasia & 43 & $14.2 \%$ \\
\hline 5 & Chronic papillary endocervicitis + Squamous \\
& metaplasia & 8 & $2.6 \%$ \\
\hline 6 & Squamous cell carcinoma & 7 & $2.3 \%$ \\
\hline 7 & Endocervical polyp & 4 & $1.3 \%$ \\
\hline 8 & Mucinous endocervical adenocarcinoma & 1 & $0.3 \%$ \\
\hline 9 & Unremarkable & 73 & $24.1 \%$ \\
\hline $\mathbf{1 0}$ & Total & $\mathbf{3 0 3}$ & $\mathbf{1 0 0 \%}$ \\
\hline
\end{tabular}

Majority number of cases showed chronic cervicitisas the main cervical pathology in $85(28.1 \%)$ cases followed by chronic papillary cervicitis in $52(17.2 \%)$ cases.

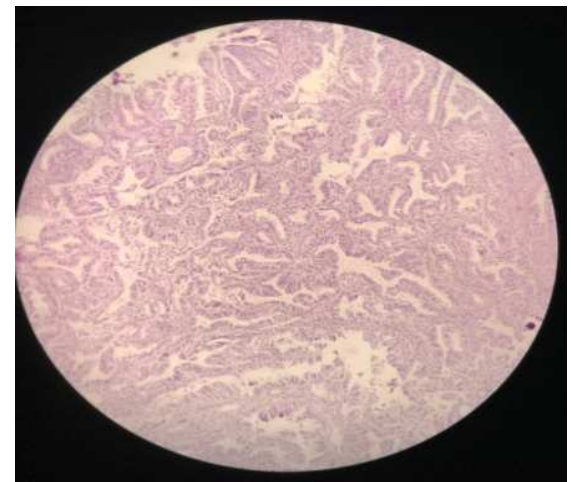

Fig-1

Figure-1: Endometrial carcinomavillogladular type (H\&E stain,20x)

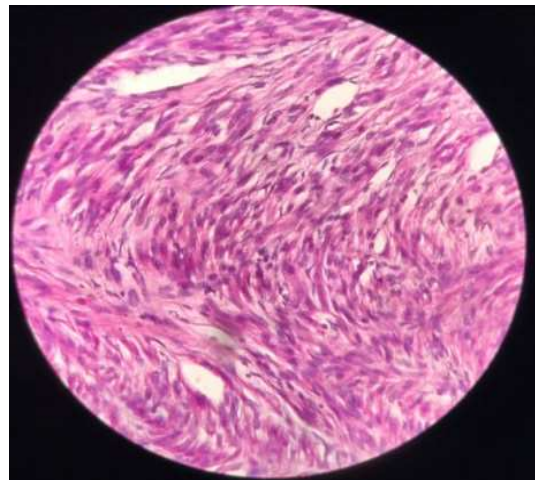

Fig-2

Figure-2: Leiomyoma (H\&E stain, 40x) 


\section{Original Research Article}

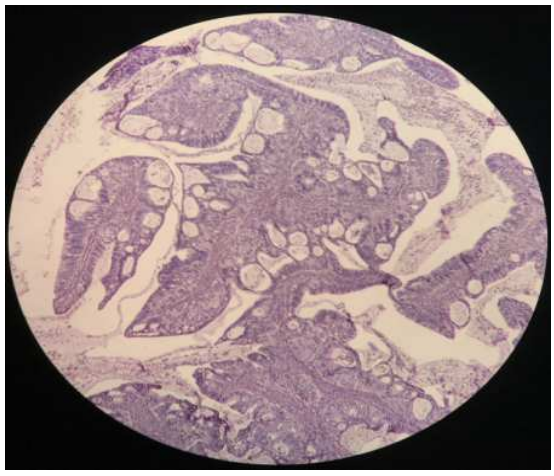

Fig-3

Figure-3: Adenomyosis (H\&E stain, 20x)

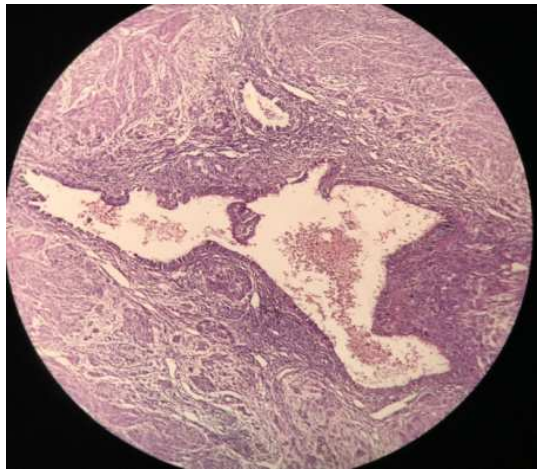

Fig-4

Figure-4: mucinous endocervical adenocarcinoma of cervix (H\&E stain, 20x)

\section{Discussion}

Hysterectomy is the most commonly performed major gynaecological surgery throughout the world. It is a successful operation in terms of less complications, symptom relief and patient satisfaction and provides definitive cure to many diseases involving uterus as well as adnexae [4]. This study was conducted to study and evaluate the patterns of lesions in hysterectomy specimens in our institution, correlate the findings with different age group and the clinical indications. In the present study half of the patients $50.8 \%$ were seen in the age group of 40-49 years.

Watts et al found most number of cases were distributed in age group of 41-50 years in an analysis of 1000 consecutive operation [5]. Other studies done by Rather $\mathrm{GR}$ et al, Ramchandran $\mathrm{T}$ et al, Ajmera et al, Chandalekha $\mathrm{J}$ et al, Raza A et al and Dhuliya V et al had similar findings [6-11].

The commonest surgical approach in the present study is abdominal hysterectomy $(69.4 \%)$ followed by vaginal hysterectomy $(32.6 \%)$ which is similar to other studies $[8,12]$. All vaginal hysterectomy was performed for uterine prolapse.

The most common clinical indication in present study was fibroid uterus $117(38.6 \%)$ cases followed by uterine prolapse 99 (32.4\%) cases. All cases of uterine prolapse were presented with second and third degree of utero-vaginal prolapse. Baral R et al observed 56 (21\%) cases of uterine prolapse [12].

In present study, atrophic endometrium was seen in 88 $(29 \%)$ of cases. It is a normal finding in postmenopausal woman but it may be associated with bleeding and therefore it is important to rule-out hyper- plasia and malignancy. Other studies by Raza A et al, Dhuliya $\mathrm{V}$ et al and Baral R et al found 26 (12.8\%), 24 $(16 \%)$ and $20(7.7 \%)$ cases respectively. [10-12]

In the present study, endometrial hyperplasia was reported in $16(5.3 \%)$ cases. Out of which 14 cases were hyperplasia without atypia and 2 cases were atypical hyperplasia. Endometrial hyperplasia was classified according to WHO classification [13]. This finding was comparable with the studies done by Dhuliya $\mathrm{V}$ et al, Ranabhat et al and Ojeda VJ et al; reported 16.6\%, 16\% and $22.3 \%$ cases of endometrial hyperplasia respectively. [11,14,15]. Raza A et alreported $0.9 \%$ of endometrial hyperplasia which is quite low than other studies [10].

Endometrial polyp was seen in $8(2.7 \%)$ of cases. Raza $\mathrm{A}$ et aland Baral $\mathrm{R}$ et al reported $1.9 \%$ and $4.9 \%$ respectively [10,12]. Three cases $(1 \%)$ of endometrial carcinoma presented in the different age group of 30-59 years were encountered in the study. All cases presented with abnormal uterine bleeding. One case $(0.3 \%)$ of low grade endometrial stromal tumor was presented with menorrhagia in 31-year-old female. Chandalekha $\mathrm{J}$ et al and Dhuliya $\mathrm{V}$ et al had similar findings [9,11].

One 27 year old patient with 9 month of amenorrhea presented with abdominal pain. Baby was delivered by caesarian section then obstetric hysterectomy was done and reported as placenta accreta.

Leiomyoma is the most common myometrial lesion in this study. Most of the studies done on the histopathological study of hysterectomy specimen till date reveals uterine fibroid are the most common pathology noted in the uterus. Studies done by Watts 


\section{Original Research Article}

WF et al, Ranabhat SK et al and Abdullah LS et al had distribution of fibroid being $41.5 \%, 34.6 \%$, and $30.3 \%$ respectively [5,10,16]. Adenomyosis 98.3\%) is the second most common myometrial pathology in this study. Adenomyosis is difficult to diagnose preoperatively as it has no specific symptoms of its own [17]. It is usually diagnosed after hysterectomy by histopathological examination [10]. 9 cases $(3 \%)$ in this study revealed the presence of both leiomyoma and adenomyosis.

Chronic cervicitis is an extremely common condition in adult females diagnosed at microscopic level. It is the commonest cervical pathology in this study, detected in $85(28.1 \%)$ cases which is comparable to that reported by Talukder et al [18]. Only eight cases (2.6\%) of malignant tumors of cervix were observed in the present study. This incidence is close to that observed by Watts WF et aland Raza A et al [5,10]. Lesions of ovaries and fallopian tubes were not included in this study.

\section{Conclusion}

In the present study majority of cases of fibroids presented with symptoms. Leiomyoma has high recurrence rate so hysterectomy is the only treatment that prevents regrowth of leiomyoma. It improves quality of life for many women.

The present study provides awareness into the wide range of histopathological patterns of lesions in uterus and cervix in hysterectomy specimens. Though the histopathological analysis correlates well with the clinical diagnosis, few lesions are also encountered as pure incidental findings.

Microscopic assessment and clinopathological correlation is necessary as grossly identifiable benign lesion may harbor in focus of malignancy. It aids to appropriate management in the postoperative period.

Hence, it is mandatory that every hysterectomy specimen, even if it grossly appears to be normal, should be subjected to detailed histopathological examination to confirm various pathological lesions, its clinical correlation and treatment modality.

Funding: Nil, Conflict of interest: None initiated, Permission from IRB: Yes

\section{References}

1. Wu JM, Wechter ME, Geller EJ, Nguyen TV, Visco AG. Hysterectomy rates in the United States, 2003. Obstet Gynecol. 2007 Nov;110(5):1091-5.
2. Nausheen F, Iqbal J, Bhatti FA, Khan AT, Sheikh S. Hysterectomy: the patient's perspective. Annals of King Edward Medical University. 2016 May; 10 (4): 339-41.

3. Silverberg SG, DeLellis RA, Frable WJ, LiVolsi VA, Wick MR. Silverberg's Principles and practice of surgical pathology and cytopathology. 4th ed. Eddinburg: Elsevier;2006.Vol.2.1935.

4. Jaleel R, Khan A, Soomro N. Clinicopathological study of abdominal hysterectomies. Pak J Med Sci. 2009; 25 (4):630-34.

5. Watts WF,Kimbrough RA Jr. Hysterectomy; analysis of 1000 consecutive operations. Obstet Gynecol. 1956 May; 7 (5):483-93.

6. Rather GR, Gupta Y, Bardhwaj S. Patterns of Lesions in Hysterectomy Specimens: A prospective study. JK Sci J Med Edu Res. 2013; 15 (2): 63-68.

7. Ramachandran $\mathrm{T}$, Sinha $\mathrm{P}$, Subramanium. Correlation between Clinicopathological and Ultrasonographical Findings in Hysterectomy. Journal of Clinical and Diagnostic Research. 2011; 5 (4): 737-740.

8. Ajmera sachin K, Mettler L, and Jonat W. Operative spectrum of hysterectomy in a German university hospital. J Obstet Gynecol India. 2006; 56 (1): 59-63.

9. Chandralekha J, Sumanlatha GR, Kartheek BVS, Bhagyalakshmi A. Prospective study of uterine corpus lesions over a period of one year in tertiary care centre. Int J Res Med Sci.2016;4:2583-7.

10. Raza AKMM. Histological Findings in Hysterectomy Specimens in a Tertiary Medical College Hospital in Bangladesh. J Cytol Histol 2017; 2 (1):3.

11. Dhuliya V, Gosai D, Jain H, Goswami H. Histopathological study of uterine and cervical lesion in hysterectomy specimen. BJkines-NJBAS. 2016; 8 (2): 23-26.

12. Baral R, Sherpa P, Gautam D. Histopathological analysis of hysterectomy specimens: one year study. Journal of Pathology of Nepal. 2017; 7: 10841086. 


\section{Original Research Article}

13. Emons G, Beckmann MW, Schmidt D, Mallmann P. New WHO Classification of Endometrial Hyperplasias. Uterus commission of the Gynecological Oncology Working Group (AGO), Geburtshilfe Frauenheilkd. 2015;75(2):135.

14. Ranabhat SK. Shrestha R. Tiwari M, Sinha DP. Subedee LR. A retrospective histopathological study of Hysterectomy with or without salpingo-ophorectomy specimens. JCMC. 2010;1(1):26-29.

15. Ojeda VJ. The pathology of hysterectomyspecimens.N Z Med J. 1979 Mar 14;89(631):169-71.
16. Abdullah LS. Hysterectomy: A Clinicopathologic Correlation. Bahrain Medical Bulletin. 2006 June; 28 (2): 1-6.

17. Mehboob R, Ahmad N. Unexpected pathology at vaginal hysterectomy for genital prolapse. Pak J Med Res 2002; 41(4):142-44.

18. Talukder SI, Haque MA, Huq MH, Alam MO, Roushan A, Noor Z, Nahar K. Histopathological analysis of hysterecto-myspecimens. Mymensingh Med J. 2007 Jan;16(1):81-4.

\section{How to cite this article?}

Patel A.S, Shah K.J. Histo pathological analysis of hysterectomy specimens in tertiary care center: two year study.Trop J Path Micro 2018;4(1):34-39.doi: 10.17511/jopm.2018.i1.06. 